dilated normally, and the patient rested well between pains which were bearable.

(iii) Poor.-Analgesia was considered poor when only slight analgesia was obtained and there was little rest between pains.

(iv) Unsatisfactory.-The result was considered to be unsatisfactory when the drug gave no benefit at all or caused the uterine contractions to cease.

Under these headings (Table IV) 47 results were considered to be good, 33 satisfactory, 11 poor, and 11 unsatisfactory. Thus $78.4 \%$ were definitely benefited by pethidine, and in $46.1 \%$ the result achieved was really good. Of the 47 cases classed as "good," 41 had spontaneous deliveries, 4 had occipito-posterior positions, 1 was a breech, and 1 a face presentation; only 4 of these patients required forceps. Among the 33 "satisfactory" cases 22 were spontaneous, 6 had occipito-posterior positions; 1 was a breech presentation; 1 had eclampsia; 1 had a contracted pelvis, and there was one set of twins; forceps were used in 10 cases. Among the 11 "poor" cases 8 were spontaneous, 1 had an occipito-posterior position, and 3 were delivered by the forceps. In the "unsatisfactory" cases, as previously detailed, 6 were normal

TABLE IV.-Analgesic Effect on Mother

\begin{tabular}{|c|c|c|c|c|c|c|}
\hline & & Cases & Prim. & Mult. & Spont. & Abnormal \\
\hline $\begin{array}{l}\text { Good } \\
\text { Sotisfactory } \\
\text { Poor } \\
\text { Unsatisfactory }\end{array}$ & $\begin{array}{l}\because \\
\because \\
.\end{array}$ & $\begin{array}{l}47 \\
33 \\
11 \\
11\end{array}$ & $\begin{array}{l}40 \\
30 \\
11 \\
10\end{array}$ & $\begin{array}{l}7 \\
3 \\
0 \\
1\end{array}$ & $\begin{array}{r}42 \\
22 \\
8 \\
5\end{array}$ & $\begin{array}{r}5 \\
11 \\
3 \\
6\end{array}$ \\
\hline
\end{tabular}

\section{Dosage Required}

With regard to dosage the figures in Table $\mathrm{V}$ would seem to show that one injection of pethidine is very often sufficient to produce good result, but if it does not then a second injection, given about an hour later, is usually all that is required. Of the "good" and "satisfactory" cases 72 required only two injections at the most; on the other hand, in cases in which, for some reason or other, labour is slow, the effect may be continued by third and fourth injections.

TABLE V.-Number of Injections Given

\begin{tabular}{|c|c|c|c|c|c|c|c|c|c|c|c|c|c|c|c|c|}
\hline & \multicolumn{4}{|c|}{ Good } & \multicolumn{4}{|c|}{ Satisfactory } & \multicolumn{4}{|c|}{ Poor } & \multicolumn{4}{|c|}{ Unsatisfactcry } \\
\hline $\begin{array}{l}\text { No. of Injections } \\
\text { Cases } \ldots\end{array}$ & $\begin{array}{r}1 \\
20\end{array}$ & 21 & $\begin{array}{l}3 \\
6\end{array}$ & 4 & $\begin{array}{l}17 \\
17\end{array}$ & ${ }_{13}^{2}$ & $\begin{array}{l}3 \\
2\end{array}$ & $\begin{array}{l}4 \\
1\end{array}$ & $\frac{1}{3}$ & $\begin{array}{l}2 \\
6\end{array}$ & $\begin{array}{l}3 \\
1\end{array}$ & $\begin{array}{l}4 \\
1\end{array}$ & $\begin{array}{l}1 \\
6\end{array}$ & $\frac{2}{4}$ & $\begin{array}{l}3 \\
1\end{array}$ & 4 \\
\hline
\end{tabular}

\section{Hyoscine and Pethidine Combination}

Of the six cases which received hyoscine in addition, to try to produce a degree of amnesia as well as analgesia, two were classed as "good," one as "satisfactory," one as "poor, and two as "unsatisfactory." These cases were treated faifly early in the investigation, and as very little benefit seemed to result from the addition of hyoscine its use was not continued. Possibly, however, we were wrong in not giving hyoscine a more extended trial, as, theoretically, the addition of hyoscine should increase the benefit, and, as will be shown later, pethidine and hyoscine together would seem to be very efficacious in producing amnesia for Caesarean section performed under local anaesthesia.

\section{General Conclusions}

Summing up the facts obtained from the treatment of these 102 patients with pethidine, we can state that the ideal analgesic drug for labour has not yet been found, but that pethidine fulfils the conditions quoted comparatively well. It has apparently no harmful effect on either mother or child; there is no tendency to produce post-partum haemorrhage; and it usually does not retard uterine contractions-in fact, in onethird of the cases it seemed to enhance uterine action appreciably. It is not always successful in producing analgesia, but it did so in enough cases (78.4\%) to make it a valuable drug to use in labour. Its administration involves no difficult routine, any slight deviation from which might be dangerous, as is so definitely the case with twilight sleep. It is rosible that the forceps rate is slightly increased by its use.

In comparison w th twilight sleev, analgesia is obtcined in approximately the same number of cases as those quoted by observers of that form of treatment, but twilight sleep has the advantage in that it produces amnesia as we!l in a larger proportion of cases; the forceps rate is, however, higher with twilight sleep owing to the fact that the co-operation of the patient in the second stage of labour is not so satisfactory as with pethidine.
There is apparently no undue excitability under pethidine, such as may occur with twilight sleep or the barbiturates.

\section{Premedication with Pethidine and Hyoscine}

For a number of years one of us (W. F. T. H.) has been trying to find a really efficient drug or combination of drugs to employ in the premedication of a patient before carrying out a Caesarean section under local anaesthesia. Caesarean sections under local anaesthesia are associated with less risk than uncer a general anaesthetic, and for women suffering from cardiac lesions, pre-eclampsia, chest conditions, etc., it is certainly the ideal method. Under local anaesthesia the operation is as a rule most satisfactory provided the woman receives adequate premedication; but of ten patients awaiting a Caesarean section are very alert, being unduly excitable because of the immediate prospect of having a baby, and even strong doses of hypnotics and sedatives have not the usual effect. Premedication with morphine and hyoscine in the accepted dosage before an operation under local or spinal anaesthesia is contraindicated, as such a dose may have a bad effect on the baby, making it difficult to resuscitate, and in some cases might cause stillbirth. We considered, therefore, that pethidine and hyoscine should be given a trial in such cases, and up to now we have used it in 6 cases, with excellent results. $100 \mathrm{mg}$. of pethidine and $1 / 150 \mathrm{gr}$. of hyoscine are injected 45 minutes before the operation, and just before the patient is taken into the theatre she is given another $100 \mathrm{mg}$. of pethidine and 1/450 gr. of hyoscine. In all cases this premedication has acted well and analgesia and amnesia were perfect, the patient usually sleeping throughout the operation and remembering nothing about it when she woke up. In each case the baby cried as soon as it was delivered, and the uterus contracted down excellently, as it always does when local anaesthesia is boing used alone. These cases may be just the "fortunate first" that often occur with any new therapy, but it would seem to be worth while to give this form of premedication an extended trial in such cases.

We desire to thank Messrs. Burroughs Wellcome for the supply of pethidine, and Messrs. Bayer Products Ltd. for the supply of dolantol-the two preparations used in this investigation. We also thank Sister Anderson and Sister Mackenzie, the day and the night labour ward sisters, for their great help and co-operation.

\section{REFERENCES}

Cleisz, L. (1924). Presse méd., 150, 1001.

Gallen, B., and Prescott, F. (1944). British Medical Journal, 1, 176

Gauss, C.' J: (1906). Arch. Gynäle., 78, 579.

Gilbert, G., and Dixon, A. B. (1943), Amer. J. Obstet. Gynec., 45, 320.

Gould, C., and Hirst, B. C. (1935).-Ibid., 30, 257

Greenwood, W. O., and Hirschman, N. (1922). British Medical Journal, 2, 667

Gwathmey, J. T.. et al., (1923). Amer. J. Obstet. Gynec., 6, 45\%

Haultain, F. W. N. (1920-1). Trans. Edinb. obstet. Soc., 47, 42.

Johnstone, R. W. (1917). Practitioner, 98, 317.

Proc. rov. Soc. Med. (1918). Discussion, Sect. Obstet. and Gynaec., 11, 1

Roby, C., and Schumann, W. R. (1943). Amer. J. Obstet. Gynec., 45, 313.

Schumann, W. R. (1944). Ibid., 47, 93.

Spitzer, W. (1944). British Medical Journal, 1, 179.

Sturrock, J. (1939). Relief of Pain in Labour, Sherratt and Hughes.

\section{SPONTANEOUS LOBECTOMY}

BY

\section{J. W. TAYLOR, M.B., Ch.B.}

Thoracic Surgical Officer, the General Infirmary at Leeds

During recent years it has become increasingly difficult to differentiate between a lung abscess and an empyema. There is no doubt that in many cases the infection is primarily in the lung tissue and only secondarily invades the pleural cavity. This has given rise to the term "pleuro-pulmonary abscess." In the following case the infection was so great that a complete upper-lobe lung slough became free in an empyema cavity.

\section{Case Record}

A man aged 43 was admitted to the General Infirmary at Leeds on Dec. 14, 1942, under the care of Mr. P. R. Allison. He gave the following history. On Oct. 17, 1942, he was seized with a sudden acute pain in the middle of the back while at work and rapidly developed a severe cough. He became so ill that he had to be taken home and put to bed. He was febrile, and on Oct. 20 was removed to a nursing home with a diagnosis of lobar pneumonia. A course of sulphapyridine was given: $2 \mathrm{~g}$. stat. and $1 \mathrm{~g}$. four-hourly 
for 48 hours, and then $0.5 \mathrm{~g}$. four-hourly for 24 hours-a total of $17 \mathrm{~g}$. in 3 days. His temperature fell to normal on the second day, and on Nov. 3 he was discharged apparently cured.

The man improved for about a fortnight; then his cough returned with added severity and he brought up much foul-smelling greenishyellow sputum. Cough was his main symptom at this time. Vomiting occurred on several occasions, and his cough became almost incessant. A noticeable feature was that the cough was made worse by movement: he was more free from the paroxysms of coughing when supine than when in an upright position. His temperature varied from $99^{\circ}$ to $101^{\circ}$, and clinical examination on Dec. 8 showed that there was an effusion at the right apex. $X$-ray examination on Dec. 10 confirmed this. Aspiration of the right chest in the sixth interspace in the mid-axillary line produced pus which on culture gave a profuse nearly pure growth of $B$. friedländeri. The patient was admitted as a case of post-pneumonic empyema on Dec. 14 : temperature $99.6^{\circ}$, pulse 84 , and respirations 26.

Operation Notes.-Premedication consisted of morphine gr. 1/4, atropine gr. 1/100, and scopolamine gr. 1/150. The skin and subcutaneous tissue in the right upper chest were infiltrated with $0.5 \%$ planocaine, and aspiration of the chest in the sixth interspace in the mid-axillary line produced pus. A portion of the sixth rib was removed and the parietal pleura was opened. A large apical cavity was entered and $45 \mathrm{oz}$. of thick green pus was withdrawn. During a violent fit of coughing a slough of the whole of the right upper lobe was expelled from the wound, being followed by a gush of foul-smelling pus. A large drainage-tube was inserted into the cavity, and the skin lightly sutured and a light dressing applied. The lung slough measured 20 by 8 by $6 \mathrm{~cm}$. It had a grey ragged appearance and was pitted with small holes.

Post-operative Progress. - On return from the theatre the patient's general condition was good: temperature $99.6^{\circ}$, pulse 96 , and respirations 32. Cough, which was spasmodic, was relieved with linctus heroin 2 dr. t.d.s. Drainage was profuse, and his temperature, pulse, and respirations, reached normal levels on the third post-operative day. $X$-ray examination at this time showed that the tube was in good position and that there was no fluid level in the cavity. Satisfactory progress was maintained, and on Dec. 22 a thoracoscope was passed into the cavity. Clean pink pleura could be seen all round except on the lower and posterior part, where the dappled surface of the lower and middle lobes could be made out. The root structures were plainly visible, and at least three large bronchial openings could be seen. There was a polypoidal projection from what seemed to be the pulmonary artery, which was presumably organizing blood-clot.

Convalescence continued to be satisfactory and drainage gradually decreased. Apart from a slight morning cough the patient was now entirely free. On Jan. 23, 1943, he was allowed to get up, and on Feb. 19 was discharged from the hospital with a self-retaining catheter in position in the cavity. The tube was changed frequently, and $x$-ray examinations were made at intervals of about three weeks. The tube was finally removed on June 2 , and the sinus rapidly closed. $X$-ray examination showed that there was then still a cavity at the right apex, with at least one patent bronchus at its lower end. The patient is now (June 20) quite well, free from cough and dyspnoea, is gaining weight, and has started work.

\section{Comment}

The illness began with an attack of lobar pneumonia, which was followed by a period of recovery. This was interrupted by the appearance of excessive cough, which was productive of thick greenish-yellow sputum, with attendant symptoms of malaise and pyrexia. Clinical examination some two months later suggested an empyema, and drainage was indicated. At this time the cough was noted to be positional: the patient coughed more when he was upright than when flat in bed. The presence of $B$. friedländeri in the pus from the cavity was a rare and unexpected finding. Removal of the tube six months after drainage was started still left a cavity in the right upper zone. This cavity is draining into a patent bronchus on its lower and medial aspect. Up to now the presence of a cavity has not given rise to any symptoms. The question of an apical thoracoplasty must, however, be kept in mind, so that the cavity may be closed completely if it should again give rise to any symptoms.

\section{Summary}

One case of spontaneous lobectomy is described. The finding of a nearly pure culture of $B$. friedländeri in the pus from an empyema is noted as a rare event.

For permission to describe this case I have to thank Mr. P. R. Allison, under whose supervision it was while in hospital.

\section{Medical Memoranda}

\section{"Spinning the Occipito-posterior"}

In a fairly concentrated experience of obstetric practice (hospital, consulting, and private) spread over 25 years, at least 500 cases of occipito-posterior presentation, at a very moderate estimate, must have been treated (probably many more). During this period a method of treatment, feasible in a limited number of cases only, has been thrust upon me by Nature's own ordinance rather than by any skill or genius on my own part. I have termed this method, perhaps rather fancifully, "spinning the occipito-posterior."

The method depends upon the combination of several favourab'e circumstances, some of which are partly under medical control. These are as follows :

1. The membranes must be intact.

2. The head must not be absolutely jammed in the lower strait.

3. There must be at least two to three fingers dilatation.

4. There must be no disproportion between the head and the pelvis.

5. The attempt should be made within 24 hours (probably) - of the onset of "painful contractions of poor quality" so characteristic of occipito-posterior presentations.

In such cases the usual approved method of treatment is by analgesics and psychological control of the patient.

There is an alternative. In the course of examination, to determine position and progress, a two-finger vaginal examination should, if possible, be made. With a knowledge of " intact membranes," the head may be pushed upwards, between pains, possibly half an inch or more into the cavity of the pelvis. The result is that liquor amnii can pass down on all sides of the head. so that, for practical purposes, it again floats in the lower part of the amniotic sac. Should the pressure upwarcs be timed to coincide with the onset of a contraction, the head will sometimes spin completely round to occipito-anterior practically instantaneously. Retaining this position by fundal pressure and promptly rupturing the membranes and letting off liquor will lead to a reasonably rapid and normal delivery.

It is obvious that this method has a limited application, but might possiblv be used much more often if the necessary conditions were looked for and the attempt made.

Bath.

$$
\text { Douglas A. Mitchell, }
$$

M.D.Lond., F.R.C.S.Ed., M.R.C.O.G.

\section{Fracture of the Neck of the Femur after Amputation}

Fracture through the neck of the femur due to hyperatmic decalcification-the fatigue type of fracture-is allied architecturally to the lesion described below. A search of the literature being fruitless, it was thought worth while to record the following case both as a matter of interest and as a warning.

\section{CASE REGord}

A shunter aged 43 was admitted to the orthopaedic department of Peterborough Memorial Hospital on July 24, 1943, an express train having run over his right foot, amputating it close to the ankle-joint. After resuscitation, as he was profoundly shocked, an amputation was performed $5 \frac{1}{2}$ in. from the inner side of his kneejoint. Three weeks later he was discharged from hospital, but attended for a considerable time for stump and hip exercises. In due course he was measured for his artificial limb by one of the best makers. On Dec. 8 this arrived, and on the following day he walked over to the hospital to show me his prowess. On Dec. 11, when some miles outside Peterborough, he felt something give in his hip-joint while stepping from a high pavement to the road. As he could not move he was brought to hospital again by ambulance. Radiographs showed a typical transcervical fracture and also the typical appearance of a disuse atrophy. A few days later a vitallium nail was driven across the fracture. After three months, as there was sound bony union, weight-bearing was started-this time very gradually. Now he is doing everything a modern artificial limb permits.

\section{COMMENT}

This case, in my opinion, is a mixture between the fatigue type of fracture and that due to disuse atrophy, the precipitating factor no doubt being the latter, the hyperaemia calised by the unaccustomed activity helping to decalcify still further the weakened bony structure. This case serves as a warningto me, at any rate-that weight-bearing should be given in graduated doses after an amputation, and no such warning or similar cases to this has been recorded. 